\title{
Jogo de cartas como metodologia de ensino de Astronomia para a educação básica
}

\section{Juego de cartas como metodolodía de enseñanza del Astronomía para la educación basica}

\author{
Mairon Melo Machado (mairon.machado@iffarroupilha.edu.br) \\ Instituto Federal Farroupilha - Campus São Borja (IFFAR) \\ Cátia Andressa Fortes Buzanello (cbuzanello@gmail.com) \\ Instituto Federal Farroupilha - Campus São Borja (IFFAR) \\ Priscyla Christine Hammerl (priscyla.hammerl@iffarroupilha.edu.br) \\ Instituto Federal Farroupilha - Campus São Borja (IFFAR)
}

Resumo: A Astronomia é uma área de conhecimento que desperta o interesse de alunos e professores. Seu estudo traz hipóteses sobre a formação do Sistema Solar, constituição de planetas, estrelas, além da origem e evolução da vida na Terra. Com o objetivo de estimular o estudo da Astronomia, este trabalho produz um jogo de cartas que auxilia na aprendizagem de Astronomia para alunos de escolas de nível fundamental e médio. $\mathrm{O}$ jogo, denominado Super Trunfo de Astronomia, foi aplicado para um total de 40 alunos em ambos os níveis de ensino, 20 de cada nível. Os resultados em termos de respostas para as perguntas dos autores pós-atividade foram extremamente satisfatórios quanto ao processo ensino-aprendizagem, com os alunos adquirindo conhecimentos iniciais sobre esse importante ramo da Ciência.

Palavras-chave: Ensino de Astronomia; Jogos Educativos; Metodologias Alternativas; Educação.

Resumen: La astronomía es una área de conocimiento que despierta el interés de estudiantes y maestros. Su estudio trae hipótesis sobre la formación del Sistema Solar, la constitución de planetas, estrellas y el origen y evolución de la vida en la Tierra. Con el objetivo de estimular el estudio de la astronomía, este trabajo produce un juego de cartas que ayuda en el aprendizaje de la astronomía para estudiantes de escuelas primarias y secundarias. El juego, llamado Super Trunfo de Astronomia, se aplicó a un total de 40 estudiantes en ambos niveles, 20 de cada nivel. Los resultados para respuestas a las preguntas de los autores posteriores a la actividad fueron extremadamente satisfactórios con respecto al proceso de enseñanza-aprendizaje, con los estudiantes obtuvieron un conocimiento inicial sobre esta importante tema de la ciencia.

Palavras-chave traduzidas: Enseñanza del Astronomía; Juegos Educativos; Metodologías Alternativas; Educacón.

\section{INTRODUÇÃO: A ASTRONOMIA NA EDUCAÇÃO BÁSICA}


A Astronomia é considerada a mais antiga das Ciências. Seus primeiros registros são de aproximadamente 3000 a. C., através de registros dos povos chineses, babilônios, assírios, e egípcios. O conhecimento adquirido por esses povos era utilizado com objetivos práticos, como relataram Oliveira e Saraiva

Naquela época, os astros eram estudados com objetivos práticos, como medir a passagem do tempo (fases calendários) para prever a melhor época para o plantio e a colheita, ou com objetivos mais relacionados a astrologia, como fazer previsões do futuro. (OLIVEIRA, SARAIVA, 2014, p. 01).

Os conteúdos relacionados à Astronomia têm um potencial de motivar alunos e professores, visto que se pode utilizar da universalidade e interdisciplinaridade desta área como ressaltam Langhi e Nardi,

\begin{abstract}
Pois há nela, intrínseca, uma universalidade e um caráter inerentemente interdisciplinar, sendo de fundamental importância para uma formação minimamente aceitável do indivíduo e cidadão, profundamente dependente da ciência e das tecnologias atuais. Entendemos que a astronomia é especialmente apropriada para motivar os alunos a aprofundar conhecimentos em diversas áreas, pois, o ensino da astronomia é altamente interdisciplinar (LANGHI E NARDI, 2012, p. 108).
\end{abstract}

Além disso, essa área permite um estudo mesmo sem equipamentos rebuscados, um laboratório a céu aberto, e crateras de impacto, que podem ser visitadas pelos estudantes e professores. E utilização de metodologias que podem sair do contexto de sala de aula e promover aprendizagens brincando.

A utilização da Astronomia em sala de aula vem sendo uma ferramenta útil para despertar o interesse dos estudantes. De acordo com, Farel et. al. há "necessidade de implementá-la como parte dos conhecimentos adquiridos no ensino básico dos jovens que terão a oportunidade de experimentar e desvendar os segredos que nos circunda e que tanto se mostra uma área de possibilidades" (FAREL et. al., 2017). A Astronomia portanto, possibilita uma construção do indivíduo como parte do universo, proporcionando caminhos para reflexões sobre seu papel no meio no qual está inserido.

Porém, a falta de acesso ao conhecimento científico tem cada vez mais afastado jovens e adultos da Ciência. Sites, canais online ou redes sociais, divulgam matérias e notícias que acabam se tornando mais atraentes do que olhar para o céu noturno e tentar entender o que se vê lá. Faz-se necessário buscar por metodologias de ensino que aproximem o cotidiano dos educandos dos conceitos relacionados a Astronomia, e que ao mesmo passo provoque o pensamento crítico, científico e filosófico proporcionando uma educação cidadã. 
Com o surgimento da Base Nacional Comum Curricular (BRASIL, 2016) e a criação dos Parâmetros Curriculares Nacionais (BRASIL, 1998; 1999; 2002a; 2002b), tópicos de Astronomia devem agora ser abordados também na educação básica, ao longo de todos os seus anos, de diferentes formas. Com isso iniciaram-se estudos sobre metodologias de ensino de Astronomia e até o presente momento, ainda existe uma grande discussão sobre como deve ocorrer o processo de ensino de Astronomia.

Esse trabalho utilizou o jogo de cartas como metodologia de conhecimento, para incentivar professores e alunos a se interessarem por Astronomia. Dentro dos diversos ramos da Astronomia, o estudo dos planetas e satélites naturais do Sistema Solar, estudo de estrelas, asteroides, cometas, meteoros e meteoritos, é uma forma atraente de levar esse importante ramo da Ciência para as salas de aula, seja no Ensino Fundamental ou no Ensino Médio. Esses tópicos inclusive estão previstos na BNCC.

Para tal, foram realizadas duas oficinas com 20 alunos de Ensino Médio e 20 alunos de Ensino Fundamental, onde foi proposta a atividade de jogar as cartas criadas pelos autores, e após o jogo, identificar se questões pertinentes ao Sistema Solar e a Astronomia Básica poderiam ser respondidas por eles. $\mathrm{O}$ desenvolvimento do trabalho será da seguinte forma: primeiramente, apresenta-se a funcionalidade do jogo como uma forma alternativa de metodologia de ensino. Passa-se às regras do jogo, bem como a construção do jogo didático, para introduzir conceitos básicos do estudo de Astronomia. $\mathrm{Na}$ sequência, a aplicação das oficinas e os resultados extraídos das mesmas, além de considerações finais.

\section{O JOGO COMO METODOLOGIA DE ENSINO}

A utilização de metodologias diferenciadas vem sendo cada vez mais utilizada no contexto escolar, visando uma melhor aprendizagem do aluno. Para tal, a utilização de atividades práticas é defendida por Langhi e Nardi, pois as atividades experimentais dariam poucas possibilidades de intervenção. Seriam receitas prontas, não oportunizando a possibilidade ao aluno de tentar fazer outras verificações, visto que a atividade experimental geralmente tem o seu roteiro específico para a confirmação da teoria previamente definida (LANGHI, NARDI, 2012).

O uso de jogos em sala de aula visa ser uma importante ferramenta de ensino. JOUCOSKI et. al. (2011, p. 02) ressaltam que "os jogos incentivam trabalho em equipes e a interação professor-aluno, auxiliando o desenvolvimento de raciocínio e habilidades. 
Quando o jogo é usado com o objetivo de ser um instrumento no meio escolar o denominamos jogo didático". Os jogos possuem grande importância na educação, pois além do aluno compreender os conteúdos, os mesmos estarão aprendendo de forma divertida, de forma lúdica, e sem a preocupação de terem que decorá-los, facilitando assim, a aprendizagem. Também são fundamentais para a eficiência no incentivo, socialização e gerar confiança dos alunos com maiores dificuldades de aprendizado, auxiliando na mediação do processo de ensino e aprendizagem (DA SILVA, 2019).

Os jogos de cartas como uma metodologia para o ensino de Astronomia, visam dar autonomia aos alunos, possibilitando assim, que o jogador possa buscar mais informações além daquelas contidas em cada carta, tanto dos dados astronômicos, quanto para terem noção de aspectos tais como dimensão, período de rotação, densidade, massa, temperatura, periélio, magnitude, longitude, peso, luminosidade, entre outras características que podem ser modificadas ao serem feitas a montagem das cartas.

A utilização do jogo de cartas como metodologia de aprendizagem, visa incentivar professores e alunos a se interessarem por Astronomia. A partir do jogo proposto verifica-se uma possibilidade de desenvolver esta área da ciência em regiões afastadas das regiões metropolitanas, nas quais há grandes centros de estudo e divulgação da Astronomia.

O jogo é um fim em sim mesmo ou um instrumento com objetivos bem determinados? Segundo Friedmann (1996, p.17) há respostas diferentes a cada questão: em primeiro lugar a criança pode brincar por puro divertimento em relação de trocas entre seus pares, adultos ou outras crianças, com o jogo tendo um fim em si mesmo. Outra opção é pensar no jogo como uma ferramenta lúdica como meio educacional para atingir objetivos preestabelecidos, auxiliando o desenvolvimento da criança (JOUCOSKI et. al., 2011, p. 03).

\section{SUPER TRUNFO DE ASTRONOMIA}

O jogo de cartas desenvolvido nesse trabalho chama-se Super Trunfo de Astronomia. Ele é baseado no tradicional jogo de cartas Super Trunfo, que fez sucesso nos anos 70 e 80, e ainda hoje, encanta e diverte crianças e adultos ao redor o mundo. $\mathrm{O}$ jogo original objetiva a análise das informações contidas nas cartas, e aquele jogador que tiver a carta com maior valor na informação escolhida, ganha a carta. No final, o jogador que obtiver mais cartas é o ganhador do jogo. 
O jogo é dividido em seis grupos de cartas, em que cada grupo possui oito cartas, formando assim um jogo com 48 cartas. Ele propicia com que os jogadores, além de se divertirem com o jogo, também aprendam algumas informações básicas dos temas escolhidos de Astronomia. Os conjuntos representam planetas do sistema solar, estrelas, cometas, luas, crateras de impacto terrestres, asteroides e meteoritos. As cartas ficam viradas para baixo, onde é possível identificar cada grupo de cartas pela letra que possui no seu verso (ver imagens ao longo do texto). Pode ser jogado per em duplas ou quartetos. Os participantes irão escolher as suas cartas, que devem ser divididas de forma igual. $\mathrm{O}$ jogo possui um dado, o qual é jogado para o jogador saber qual grupo será utilizado para fazer a análise das cartas. Ganha o jogo aquele que obtiver o maior número de cartas.

As escolhas dos autores para confecção das cartas foram baseadas principalmente em nomes conhecidos e/ou corpo celeste com valor de relevância para o jogo. Começando pelo grupo de cartas das estrelas, ele é simbolizado pela letra E. Possui como informações raio (em metros), massa (em quilogramas), luminosidade (em erg/s) e temperatura (em K). Foram utilizadas as seguintes estrelas: Sol, Alpha Mensae, Cygni A, Estrela de Van Biesbroeck, Orions C, Orions $\bullet$, e Gamma Berenice. A Figura 1 apresenta um exemplo deste grupo, com a estrela Sol, sendo a frente da carta, trazendo as informações (esquerda), e o verso contendo a letra E (direita).

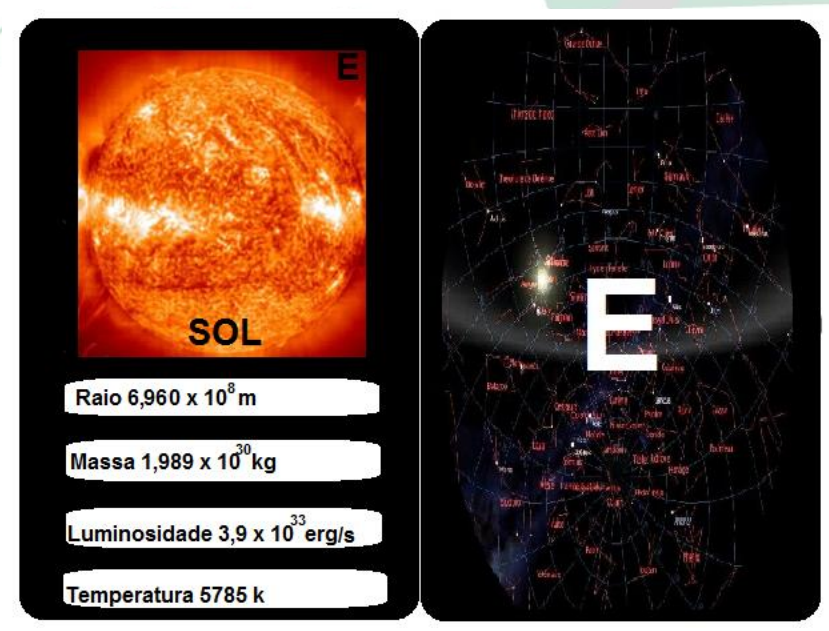

Figura 1: Exemplo de cartas da categoria estrelas, com a frente (esquerda) e o verso (direita).

O grupo dos planetas é simbolizado no verso pela letra P. Ele utiliza como informações o diâmetro (em quilômetros), massa (em quilogramas), período de rotação (em horas) e temperatura média de cada planeta $\left(\mathrm{em}^{\circ} \mathrm{C}\right)$ do Sistema Solar. Foram utilizados os oito planetas existentes no nosso Sistema Solar. A Figura 2 apresenta um 
exemplo de carta deste grupo, com o planeta Terra sendo a frente da carta, trazendo as informações (esquerda), e o verso contendo a letra P (direita).
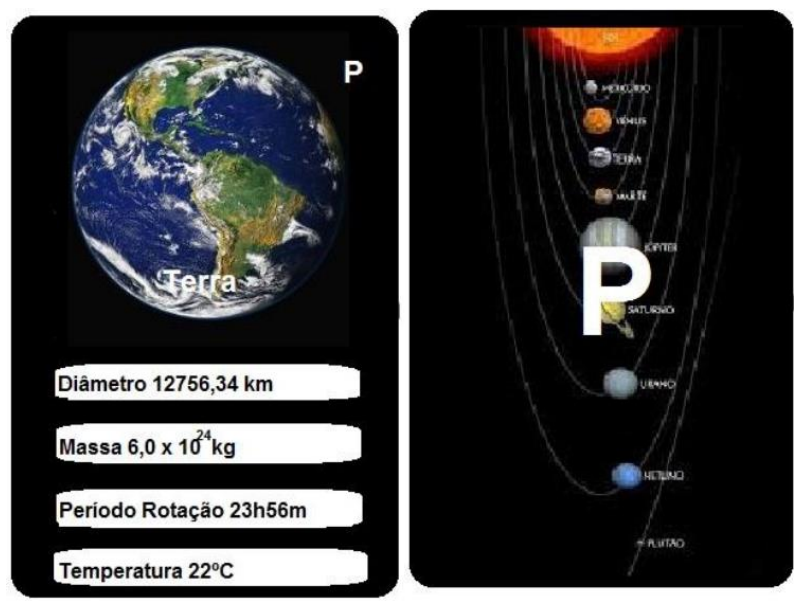

Figura 2: Exemplo de cartas da categoria planetas, com a frente (esquerda) e o verso (direita)

O grupo de cartas dos cometas é identificado pela letra C. Ele possui as informações período (em anos), periélio (em unidades astronômicas) e magnitude, considerada a magnitude aproximada do último retorno do cometa a uma Unidade Astronômica (UA) da Terra e do Sol. Os cometas escolhidos foram Encke, Clarck, Kopff, Biela, Oterma-Stephan, Gale, Halley e HaleBopp. A Figura 3 apresenta um exemplo, com o cometa Halley sendo a frente da carta (esquerda), e o verso contendo a letra C (direita).
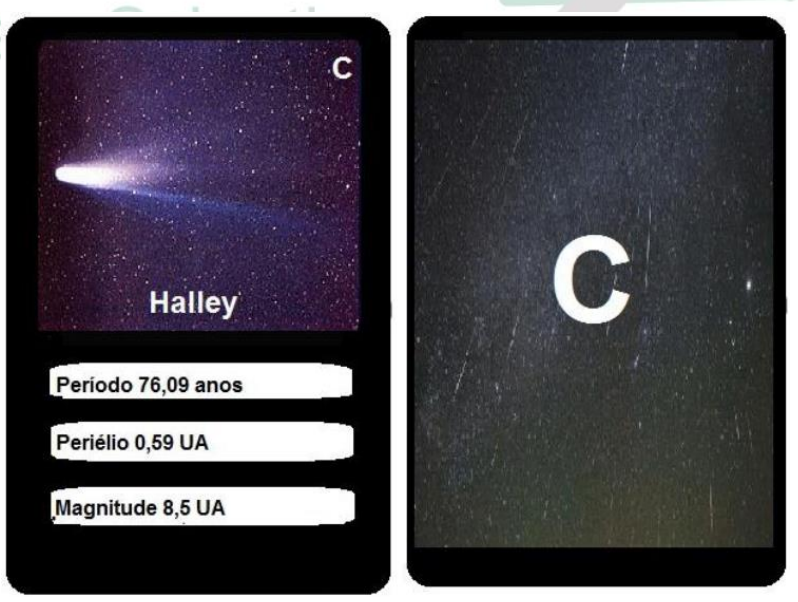

Figura 3: Exemplo de cartas da categoria cometas, com a frente (esquerda) e o verso (direita).

O grupo Luas ${ }^{1}$ é identificado pela letra L em seu verso. Ele apresenta alguns dos satélites naturais de determinados planetas, e traz as informações diâmetro (em

\footnotetext{
${ }^{1}$ Os autores chamam o grupo de Luas, com maiúsculo, apenas para seguir a notação considerada no jogo e facilitar a identificação das cartas apenas por uma única letra.
} 
quilômetros), massa (em quilogramas), período de rotação (em dias) e densidade (em $\mathrm{g} / \mathrm{cm}^{3}$ ). Os satélites naturais escolhidos foram a Lua (Terra), Deimos e Fobos (Marte), Ganímedes e Europa (Júpiter), Titã (Saturno), Oberon (Urano) e Tritão (Netuno). A Figura 4 apresenta um exemplo de carta deste grupo, com Ganímedes sendo a frente da carta (esquerda), e o verso contendo a letra L (direita).
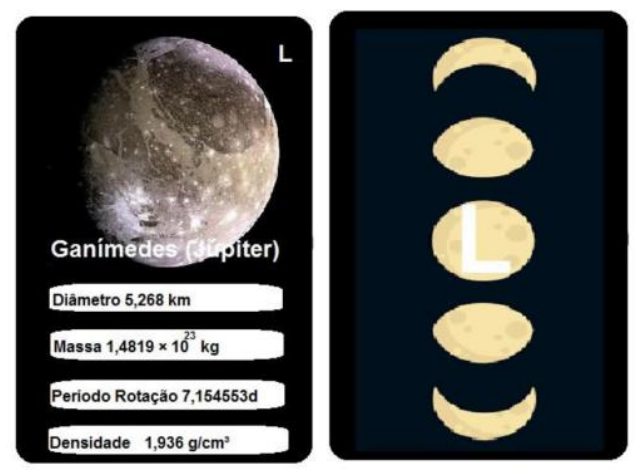

Figura 4: Exemplo de cartas da categoria luas, com a frente (esquerda) e o verso (direita).

O quinto grupo de cartas é os das Crateras de impacto, identificada pela letra I, que traz as informações dimensão (em quilômetros), idade (em Mega-anos) e localização. Foram utilizadas apenas crateras terrestres, sendo as escolhidas Vista Alegre (Santa Catarina, Brasil), Chicxulub (Yucatán, México), Vredefort (África do Sul), Popigai (Rússia), SudburyBasin (Ontário, Canadá), Manicouagan (Quebec, Canadá), Jarau (Quaraí, Brasil) e Domo do Araguainha (Goiás, Brasil). A Figura 5 apresenta um exemplo de carta deste grupo, com a Cratera de Chicxulub sendo a frente da carta, trazendo as informações (esquerda), e o verso contendo a letra I (direita).
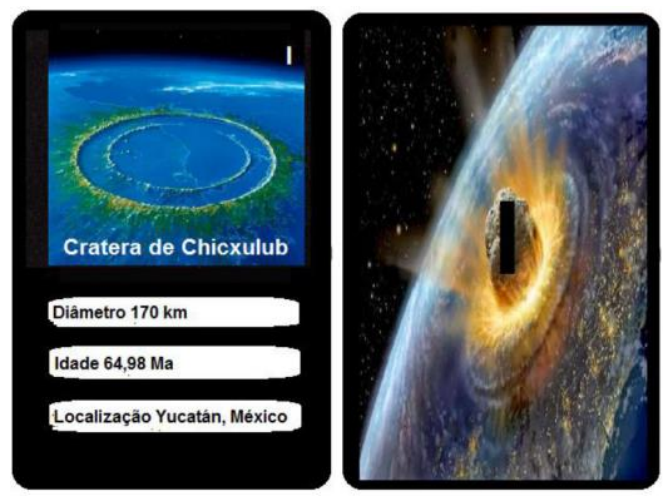

Figura 5: Exemplo de cartas da categoria Crateras de Impacto, com a frente (esquerda) e o verso (direita). 
O sexto e último grupo de cartas é o de Asteroides e Meteoritos, identificadas com

a letra A, que possuem informações diâmetro (quilômetros), ano de descoberta e massa (em quilogramas). Foram selecionados os Asteroides Ceres, Vesta, Herculina e Hebe, o os Meteoritos, Willamette, Bacubirito, Hoba e Santa Catharina. A Figura 6 apresenta um exemplo de carta deste grupo, com o Asteroide Ceres sendo a frente da carta, trazendo as informações (esquerda), e o verso contendo a letra A (direita).

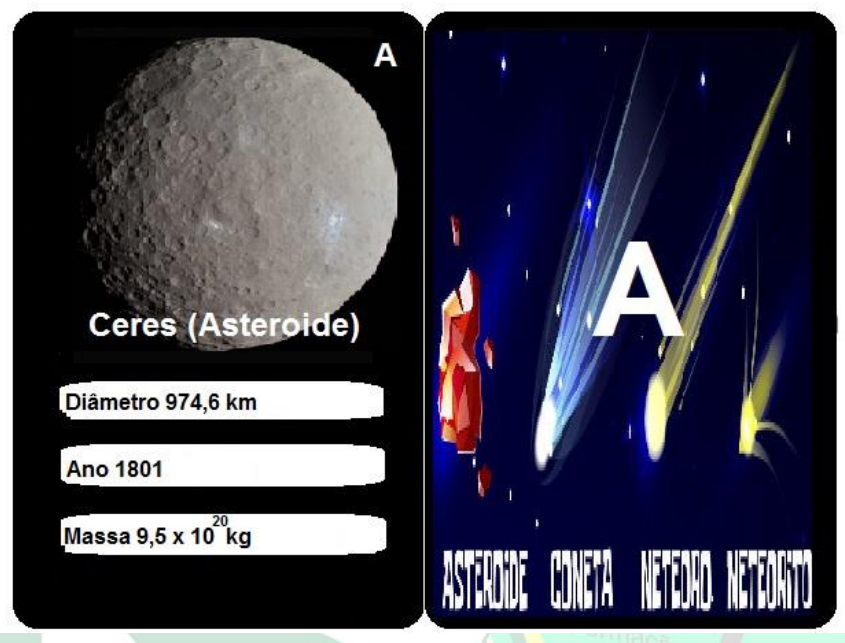

Figura 6: Exemplo de cartas da categoria Asteroides e Meteoritos, com a frente (esquerda) e o verso (direita).

Com as cartas em mãos, foram realizadas as atividades de jogos. Durante os meses de agosto e setembro de 2019, foram realizadas atividades com alunos do Ensino Médio e Ensino Fundamental na cidade de São Borja, Rio Grande do Sul. Foram selecionados vinte alunos dos três anos de Ensino Médio, da escola Instituto Federal Farroupilha (agosto), e trinta alunos do $7^{\circ}$ e $8^{\circ}$ ano da rede pública estadual de São Borja (setembro). Os alunos foram selecionados por meio de inscrição, através de convites realizados nas escolas junto ao projeto de extensão Astronomia na Escola. Esse projeto está em atividade desde 2011 na cidade de São Borja, tendo como objetivo levar o conhecimento da Astronomia aos alunos de escolas públicas na região oeste do Rio Grande do Sul, usando do ensino e incentivo a Astronomia Amadora para despertar o interesse pela Astronomia e pelas Ciências (GOTTFRIED et al, 2018). Isso ocorre através de visitas às escolas, participação em eventos e realizações de observações astronômicas. Até hoje, o projeto já totalizou mais de cinco mil participantes.

Antes das atividades, os autores fizeram uma breve apresentação sobre Astronomia básica, ressaltando principalmente assuntos relacionados com estrelas, planetas, satélites naturais, crateras de impacto, asteroides e meteoros. Após a 
explanação, foram passadas as regras do jogo, e assim, foram divididos os alunos em seis grupos de cinco alunos, por nível de ensino, os quais foram jogando uns contra os outros de forma aleatória.

No final da atividade, após uma hora, as cartas foram recolhidas, e assim, passouse para uma terceira etapa, com perguntas pertinentes ao jogo.

A tabela a seguir apresenta algumas das questões voltadas exclusivamente para o aprendizado (esquerda) e o índice de acertos (direita), em ordem de acertos. As demais questões variaram de nome, escolarização, idade, bairro onde mora, entre outras informações pertinentes para posterior entrega de certificados de participação na atividade.

\begin{tabular}{|l|c|}
\hline \multicolumn{1}{|c|}{ Questões } & Índice de acertos (\%) \\
\hline $\begin{array}{l}\text { O Sol é a maior estrela do universo, e tão } \\
\text { pouco é uma das maiores? }\end{array}$ & 100 \\
\hline Qual o período do cometa Halley? & 100 \\
\hline $\begin{array}{l}\text { Qual a Cratera de Impacto de maior } \\
\text { diâmetro, bem como sua localização? }\end{array}$ & 100 \\
\hline Qual o maior satélite natural de Júpiter? & 100 \\
\hline Onde localiza-se a Cratera do Jarau? & 97,5 \\
\hline $\begin{array}{l}\text { Que ano foi datado o meteorito Santa } \\
\text { Catharina? }\end{array}$ & 92,5 \\
\hline Qual o planeta de menor temperatura? & 82,5 \\
\hline Quais as grandes crateras canadenses? & 77,5 \\
\hline Qual é o planeta de Deimos? & 77,5 \\
\hline Qual o planeta com maior temperatura? & 70 \\
\hline $\begin{array}{l}\text { Qual a diferença entre Cometa e } \\
\text { Asteroides? }\end{array}$ & 55 \\
\hline O que é Periélio? & 45 \\
\hline
\end{tabular}

Quando questionados se gostaram da atividade, os alunos foram unânimes em responder que sim, e perguntaram se o jogo poderia ser levado para casa. Como as atividades foram realizadas em meses distintos, não foi possível entregar as cartas para os alunos levarem para casa, mas ficou a emoção de ver a alegria dos alunos pedindo para jogar novamente mesmo após encerradas as atividades.

\section{CONSIDERAÇÕES FINAIS}


Esse trabalho apresentou a construção do jogo didático, como metodologia de ensino, para introduzir conceitos básicos do estudo de Astronomia, bem como aplicações do jogo em sala de aula. A utilização dos jogos educativos e lúdicos é de extrema importância para um ensino-aprendizagem significativo, visto que, o aluno aprende brincando, de forma descontraída e sem o peso dos mesmos terem que aprender o conteúdo de forma pressionada. Além disso, atividades diferentes em sala de aula tiram os alunos da rotina maçante que é copiar do quadro.

Foi de suma importância ter o contato com essas metodologias que se diferenciam do tradicional, pois são maneiras que chamam a atenção dos alunos, e preparam o aluno para ter autonomia na busca de novos conhecimentos. A utilização do ensino de Astronomia em sala de aula vem sendo uma ferramenta útil para despertar o interesse dos estudantes. O seu papel, além de promover no público o interesse por esta área, traz uma aproximação pela Ciência em geral.

Durante as atividades com alunos de Ensino Médio e Ensino Fundamental, foi possível verificar que os mesmos conseguiram adquirir conhecimentos básicos sobre Astronomia Elementar, tais como diferenciar algumas estrelas (e saber que o Sol é uma estrela pequena no espaço), conhecer alguns satélites naturais, diferenciar meteoritos, meteoros e asteroides, ou ainda, saber que existem crateras causadas por impactos de asteroides na Terra há muitos anos atrás.

A proposta apresentada aqui não se esgota. Sugere-se temáticas que possam ser abordadas em outras pesquisas, criando novas cartas e ampliando o leque de informações a respeito de Astronomia. Porém, foi visível que o jogo Super Trunfo da Astronomia pode ser uma ferramenta colaborativa para inserir os alunos da Educação Básica nessa importante área do ensino, e também de realizar as habilidades e competências exigidas pela Base Nacional Comum Curricular e pelos Parâmetros Curriculares Nacionais. E aos interessados em adquirirem as cartas, pode acessar o link do blog Divulga Astronomia ${ }^{2}$ ou entrar em contato com um dos autores via e-mail que serão disponibilizadas de forma gratuita, assim como o modelo do dado e informações pertinentes ao jogo.

\section{AGRADECIMENTOS}

${ }^{2}$ https://divulgaastronomia.blogspot.com/2020/04/jogo-didatico-super-trunfo-de-astronomia.html 
Os autores agradecem a Brenda Matoso por colaborar na divulgação do jogo através de seu blog Divulga Astronomia. Um dos autores (Mairon Machado) quer agradecer à Bianca Peixoto Gottfried (in memorian), eterna esposa, eterna aluna, eterna companheira, e que foi idealizadora do projeto para o qual o trabalho desse artigo acabou sendo um dos objetivos. Saudades eternas!

\section{REFERÊNCIAS}

BRASIL. Ministério da Educação. Secretaria da Educação Básica. BNCC: Base Nacional Curricular Comum. Brasília: Ministério da Educação, 2016. Disponível em: 〈http://basenacionalcomum.mec.gov.br/images/BNCC_publicacao.pdf〉. Acesso em: 01 jul. 2019.

BRASIL. Ministério da Educação. Secretaria de Educação Média e Tecnologia. Parâmetros Curriculares Nacionais: Ensino Médio. Brasília: Ministério da Educação, 2002a.

BRASIL. PCN + Ensino Médio: Orientações educacionais complementares aos

Parâmetros Curriculares Nacionais. Ciências humanas e suas tecnologias. Brasília: Ministério da Educação, 2002b.

BRASIL. Secretaria de Educação Média e Tecnologia. Parâmetros Curriculares Nacionais: Terceiro e Quarto ciclos do Ensino Fundamental - Ciências Naturais. Brasília: MEC/SEMTEC, 1998.

BRASIL. Secretaria de Educação Média e Tecnologia. Parâmetros Curriculares Nacionais: Ciências da Natureza, Matemática e suas Tecnologias. Brasília: MEC/SEMTEC, 1999.

DA SILVA, I. V.; FONSECA, L. M.; TAVARES, C. S.; DO CARMO, A. M.; SANT'ANA, A. C. Desenvolvimento de jogos didáticos auxiliares em práticas transdisciplinares e da alfabetização científica no ensino das Ciências da Natureza, RIS - Revista Insignare Scientia, Vol 2, n. 4, p. 349-363, 2019.

FAREL, J. S.; SILVA, J. O. F; JUSTINO, F. F. S; FRANCISCO JOSÉ DIAS DA SILVA, F. J. D. A importância da inserção da Astronomia no Ensino Médio nas escolas públicas de Araruna-PB. Faculdade de Ciências da Universidade do Porto, 2017. Disponível em: 
$<$ https://editorarealize.com.br/revistas/conedu/resumo.php?idtrabalho=2473>. Acesso em: 18 ago. 2019.

GOTTFRIED, B. P.; MACHADO, M. M.; MIRANDA, B. M. A.; CERENTINI, B. P.; DOS SANTOS, A. L. Astronomia na Escola: Despertando o Interesse pela Ciência na Fronteira Oeste do Rio Grande do Sul, Revista Extensão em Foco, Palotina, no ${ }^{\circ}$, p. 55-73, 2018.

JOUCOSKI, E.; SERBENA, A. L.; MELO, C. C.; ZANON, E. K.; DOS SANTOS, J.; CHAVES, R. K. C.; REIS, R. A. A construção dos jogos didáticos de cartas colecionáveis como instrumento de divulgação científica no programa de extensão LabMóvel, In: VIII ENCONTRO NACIONAL DE PESQUISA EM EDUCAÇÃO EM CIÊNCIAS, Campinas: 2011. Disponível em <http://abrapecnet.org.br/atas_enpec/viiienpec/resumos/R0338-1.pdf >. Acesso em: 08 jul. 2019.

LANGHI, R.; NARDI, R. Educação em Astronomia: repensando Formação de professores. São Paulo: Escrituras, 2012. (Educação para a ciência, v.11).

OLIVEIRA FILHO, K. de S.; SARAIVA, M. F. O. Astronomia e Astrofísica. $3^{\text {a }}$. Ed. São Paulo: Livraria da Física, 2014. 